\title{
Application of electron backscatter diffraction to the study of phase transformations: present and possible future
}

\author{
A.-F. GOURGUES-LORENZON \\ MINES ParisTech, Centre des Matériaux, CNRS UMR 7633, B.P. 87, 91003 Evry cedex, France
}

Key words. Electron backscatter diffraction, phase transformations, scanning electron microscopy.

\begin{abstract}
Summary
This paper first underlines the main advantages, use and limitations of the electron backscatter diffraction technique from the viewpoint of phase transformations. To get a deeper understanding of physical mechanisms involved in phase transformations, several evolutions are now in progress to get an insight into both three-dimensional and real-time information. Two of them, in particular, improvement of data collection versus improvement of data processing are discussed in the second part of this paper.
\end{abstract}

\section{Introduction}

Electron backscatter diffraction (EBSD) has been used since its earliest development to characterize microstructures as products of phase transformations (Dingley \& Randle, 1992; Dingley, 2004). From the viewpoint of phase transformations, the EBSD technique has first been applied to phase identification (Dingley \& Baba-Kishi, 1986; Michael \& Goehner, 1993; Randle, 1994; Michael \& Eades, 2000; Schwarzer et al., 2000; Baba-Kishi, 2002) and to solidification (Mason \& Adams, 1994). Its use has progressively spread over many issues of phase transformations and is still expanding rapidly (Fig. 1). This is partly due to an improvement of data sets, in particular, but not only by the continuous increase in the speed of data collection. Increasing speed of EBSD systems has open new possibilities of using EBSD for, for example, quality control, in situ experiments and threedimensional (3D) tomography, but is this the only solution to all difficulties that are still encountered in characterization of phase transformations?

Up to now, EBSD has mainly been used in the field of phase transformations to revisit a variety of metallurgical issues, making use of the versatility and multi-scale capability of scanning electron microscopy (SEM). The purpose of this paper, on the basis of recently reviewed literature data

Correspondence to: A.-F. Gourgues-Lorenzon. Tel: $(+33) 160763066$; fax: $(+33)$ 1607631 50; e-mail: anne-francoise.gourgues@ensmp.fr
(Gourgues-Lorenzon, 2007), is to underline the relevance of the EBSD technique, its remaining limits and its possible evolution to improve our understanding of phase transformation products and of their resulting in-service properties.

Brief state-of-the-art summary of applications of EBSD to phase transformations

\section{EBSD: a multiple-scale technique}

The ability of the EBSD technique to make full use of the versatility of the SEM is well known. However, it is necessary to properly identify which scales are actually covered with respect to parameters that are both internal to the material (e.g. microstructure) and external to it (mechanical, thermal, magnetic fields). Thus, according to the expected properties of the product microstructure, three different scales that have been commonly, but not always explicitly, considered are distinguished in this paper.

The macroscopic scale: obtaining statistically significant data sets. At the 'macroscopic' scale, that is, of the same characteristic size as a part of a work piece, one generally addresses a high number of crystals and considers an 'averaged' material. Texture is the feature generally investigated at that scale. In many materials, texture is strongly influenced by phase transformations during processing. In particular, coupled spatial and texture information provided by EBSD is necessary to understand and to quantitatively model solidification in a non-uniform temperature gradient or fluid flow (Takatani et al., 2000).

In coarse-grained materials, one cannot consider an average material even at this macroscopic scale. Thanks to stage control, the EBSD technique is complementary to conventional X-ray diffraction (XRD) if the grain size is too coarse (typically, more than $50-100 \mu \mathrm{m}$ in size) for an average texture to be readily determined with XRD. The grain size in coarse microstructures, for example, after solidification 


\section{Number of publications}

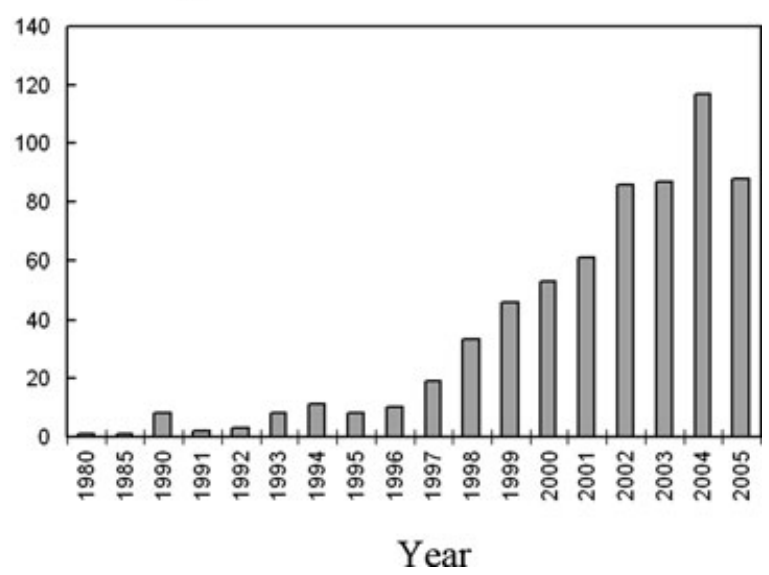

Fig. 1. Distribution of year of publication for papers reporting application of EBSD to the study of phase transformations (after the list of papers read to prepare Gourgues-Lorenzon, 2007).

in most alloys and after grain growth in $\beta$-treated Ti alloys (Davies et al., 2008) may now be readily characterized using EBSD. Large-scale inhomogeneities such as stray grains in single crystals (Stanford et al., 2004), abnormally grown or 'feathery' grains (Henry et al., 1998b) and unwanted smallgrained areas in polycrystalline materials (Xu et al., 2002) are now commonly investigated in solidification products thanks to EBSD.

The 'local' scale: high spatial resolution to characterize fine microstructural features. The very local scale, that is, one grain or a few crystals surrounding a grain boundary, is the most relevant scale to investigate both phase nucleation and early growth, as well as interface phenomena (sensitivity to corrosion, electrical conductivity, impurity atom segregation). EBSD can be used to scan small areas with high spatial resolution: $10-50 \mathrm{~nm}$ parallel to the tilt axis according to the material for conductive samples (Humphreys, 1999, 2004; Dingley, 2004), less than $1 \mu \mathrm{m}$ for non-conductive samples such as bulk ceramics and rock-forming minerals (Small \& Michael, 2001) and larger areas using beam or stage control.

Concerning phase transformations, local scale studies use EBSD to address, for example, identification of individual phases for phase diagram assessment (e.g. Zhao, 2006), investigation of the single or polycrystalline character of what appears as 'grains' or dendrites (Nagashio \& Kuribayashi, 2005) as well as subtle differences between phases such as polygonal ferrite and bainite in low alloy TRIP-aided steels (Zaefferer et al., 2004).

Unlike most transmission electron microscopy (TEM) techniques, EBSD provides field information in a quasicontinuous manner (i.e. by mapping). This kind of data can readily be exported for user-specific processing, in addition to the many features already implemented in commercial EBSD software. However, other electron diffraction techniques, using Kikuchi lines and/or diffraction patterns, have recently been developed for automated crystal orientation mapping in TEM (see e.g. Zaefferer, 2000; Rauch \& Dupuy, 2005). Many data-processing tools that have first been developed for EBSD are being transferred to process TEM-originated maps, allowing rapid characterization of microtexture with high spatial resolution, together with dislocation structures. However, the areas investigated with this method are still very small. By comparing crystal orientation maps with conventional bright-field imaging in TEM, Rauch \& Dupuy (2005) showed that many sub-boundaries readily observed in bright-field TEM images show disorientation angles that are lower than $1^{\circ}$. An advantage of the EBSD technique (and of orientation imaging techniques in TEM) is allowing definition and classification of interfaces on a quantitative, userindependent basis, provided that data cleaning procedures are properly defined and reported. However, strong limitations of EBSD in the SEM are still encountered for high-resolution studies and characterization of dislocation structures.

The 'medium' scale: specificity of the EBSD technique. The medium scale addresses a small amount of neighbouring crystals, for example, all those formed by solid-state phase transformation of a given grain of the parent phase. Mediumscale investigations using EBSD give access to both spatial location and crystal orientation, which is usually denoted as microtexture (Dingley \& Randle, 1992). Data generated with EBSD may readily be used in finite-element models together with the mechanical or thermal behaviour of phases to develop micromechanical modelling of phase transformations. Among topics that have been intensively investigated using EBSD, one can cite, for example

1. Preferred orientations induced by competitive grain growth during solidification of, for example, nickel alloys (Gandin et al., 1995; Gäumann et al., 1999; Ardakani et al., 2000; D'Souza et al., 2000), aluminium alloys (Sun \& Ryum, 1992), steels and iron alloys (Takatani et al., 2000; Hunter \& Ferry, 2002a,b), hot dip galvanized coatings (Sémoroz et al., 2002) and of a beryllium alloy (Wright \& Cotton, 1995).

2. Variant selection in solid-state phase transformations, in particular, in titanium alloys [see e.g. (Gey \& Humbert, 2002; Bhattacharyya et al., 2003; Wang et al., 2003; Banerjee et al., 2004; Stanford \& Bate, 2004; Germain et al., 2005), and in martensite and bainite in steels (see e.g. Matsuoka et al., 1999; Gourgues et al., 2000; Godet et al., 2001, 2004; Nakashima et al., 2001; Dronhofer et al., 2003; Gourgues, 2003; Morito et al., 2003, 2006; Hase et al., 2004; Furuhara et al., 2006].

Many properties could still be improved through interface engineering. First, the description of interfaces themselves could be revisited according to the relevant properties of the materials. EBSD allows quantitative definition and 
Table 1. Some examples of microtexture engineering through variant selection aided by EBSD.

\begin{tabular}{|c|c|c|c|c|c|}
\hline $\begin{array}{l}\mathrm{Ti}-\mathrm{Al}-\mathrm{Nb} \\
\text { alloys }\end{array}$ & $\begin{array}{l}\alpha_{2}\left(\mathrm{DO}_{19}\right) \\
\beta_{2} \text { (ordered } \\
\text { bcc) }\end{array}$ & O (orthorhombic) & $\begin{array}{l}\text { Changing the transformation } \\
\text { path, i.e. transforming from } \\
\text { either } \alpha_{2} \text { or } B_{2} \text { parent phase }\end{array}$ & $\begin{array}{l}65^{\circ}<001>\text { or } 90^{\circ} \text { misorientations } \\
\text { are favoured (although } 90^{\circ} \text { not } \\
\text { suited for upset forging) and } \\
30^{\circ}<001>\text { is forbidden if } \\
\text { starting phase is } \alpha_{2}\end{array}$ & $\begin{array}{l}\text { Li et al. (2004), } \\
\text { Boehlert et al. } \\
\text { (2004), Li \& } \\
\text { Boehlert } \\
(2005)\end{array}$ \\
\hline $\begin{array}{l}\text { 1.0C-Si-Mn- } \\
\text { Cr medium } \\
\text { carbon steel }\end{array}$ & $\gamma(\mathrm{fcc})$ & $\begin{array}{c}\alpha(\mathrm{bcc}) \text { or pearlite } \\
\left(\alpha+\mathrm{Fe}_{3} \mathrm{C}\right. \\
\text { eutectoid })\end{array}$ & $\begin{array}{l}\text { High applied magnetic } \\
\text { induction }(12-14 \mathrm{~T})\end{array}$ & $\begin{array}{l}\text { Increase in transformation } \\
\text { temperature, strong decrease in } \\
\text { density of low angle boundaries }\end{array}$ & $\begin{array}{l}\text { Zhang et al. } \\
\quad(2005,2006)\end{array}$ \\
\hline $\mathrm{Cu}-40 w \mathrm{t} \% \mathrm{Zn}$ & $\alpha+\beta^{\prime}$ & $\alpha$ & $\begin{array}{l}\text { Several cold-rolling }+ \\
\text { annealing sequences }\end{array}$ & $\begin{array}{l}\text { Increase in fraction of } \Sigma 3^{n} \\
\text { boundaries in the } \alpha \text { phase }\end{array}$ & Lee et al. (2003) \\
\hline
\end{tabular}

classification of grain boundaries by, for example, rotation angle, departure from exact coincidence or matching plane. The choice of such definition should rely on the expected properties of the microstructure, such as strengthening by some Hall-Petch effect, sensitivity to corrosion or to cracking, ability to arrest cleavage or short fatigue cracks, electrical conductivity and so on.

The 'grain boundary engineering' method (Watanabe, 1984) makes intensive use of EBSD as a quality control tool to process new materials with improved grain boundary properties (resistance to creep and corrosion). However, interface engineering through phase transformation and, in particular, through variant selection is still at its beginning. Variant selection has been used in some cases for this purpose, leading to promising results (Table 1). However, limiting the density number of variants is generally easier than increasing it. As many bulk phase transformations involve nucleation at grain boundaries, one could imagine appropriate variant selection through, for instance, grain boundary engineering of the parent phase followed by grain boundary nucleation of product phase. This could lead to product crystals growing into both parent grains, which could limit final segregation at these parent grain boundaries and sensitivity of those boundaries to cracking even after complete phase transformation. One can notice, for instance, how certain parent boundaries are generally difficult to reveal with chemical etching in bainitic steel microstructures. In fact, bainite packets may have locally grown on both sides in OR with parent grains, as schematically depicted in Fig. 2(a). Conversely, certain grain boundaries misorientations may help grain refinement by enhancing nucleation of closely spaced, highly misoriented crystals (Fig. 2(b)). To understand underlying mechanisms and to develop microtexture engineering through variant selection, it is necessary to infer the microtexture of the parent phase from that of the product phase. As mentioned in the previous section, the EBSD technique is an adequate tool to address this medium-scale problem.
Multiple-scale capability of the EBSD technique applied to phase transformations. Multiple-scale investigations are particularly useful for microstructures resulting from solidification (or, more generally, coarse-grained microstructures) followed by heat treatment or thermal ageing. Thanks to the development of rapid systems, a significant advantage of the EBSD technique is that all three scales (e.g. both coarse and tiny crystals) can be investigated simultaneously, as for example to characterize intergranular precipitation in coarse-grained materials such as tiny $\mathrm{M}_{23} \mathrm{C}_{6}$ carbides in austenitic stainless steels (Hong et al., 2001; Abdul Wahab \& Kral, 2005). Another typical example is variant selection at grain boundaries of the parent phase (Gey \& Humbert, 2002; Bhattacharyya et al., 2003; Banerjee et al., 2004; Stanford \& Bate, 2004; Adachi \& Tzusaki, 2005; Adachi et al., 2005). A way to grain refinement is to enhance intragranular nucleation of the new phase by inoculation with well-suited secondary phases (such as those used for acicular ferrite formation in steel welds). Again, EBSD may be helpful by allowing characterization of the role of such phases at a local scale, yet over wide areas.

\section{Does EBSD provide accurate determination of orientation relationships between phases?}

As the EBSD technique provides the full crystal orientation matrix, it has been widely used to determine orientation relationships (ORs) between crystals linked by a phase transformation, such as

1. solidified material and its substrate, for example, in welding (Wright \& Cotton, 1995; Katayama et al., 1999; Nelson et al., 1999a,b; Bezençon et al., 2003; Brooks et al., 2003; Iamboliev et al., 2003; Robino et al., 2003; Kostrivas \& Lippold, 2004),

2. precipitates and matrix, for example, in hydrided $\mathrm{Zr}$ alloy (Une et al., 2004; Une \& Ishimoto, 2006), in an austenitic stainless steel (Lewis et al., 2006), in a sintered 


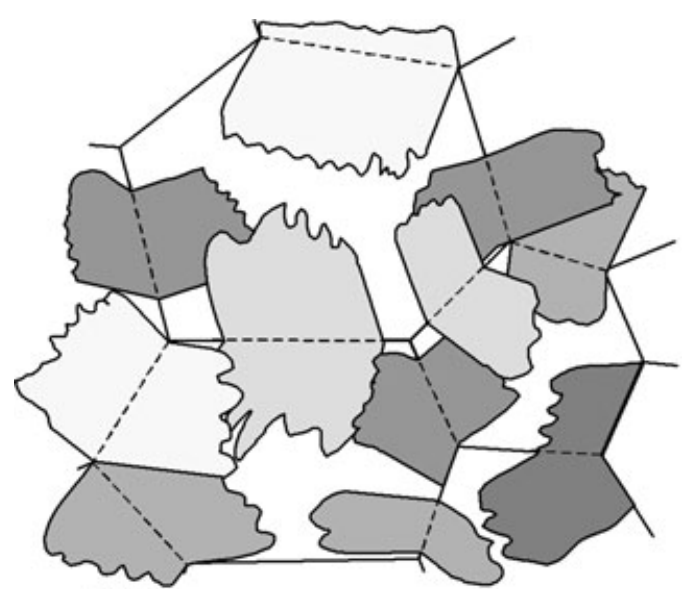

(a)

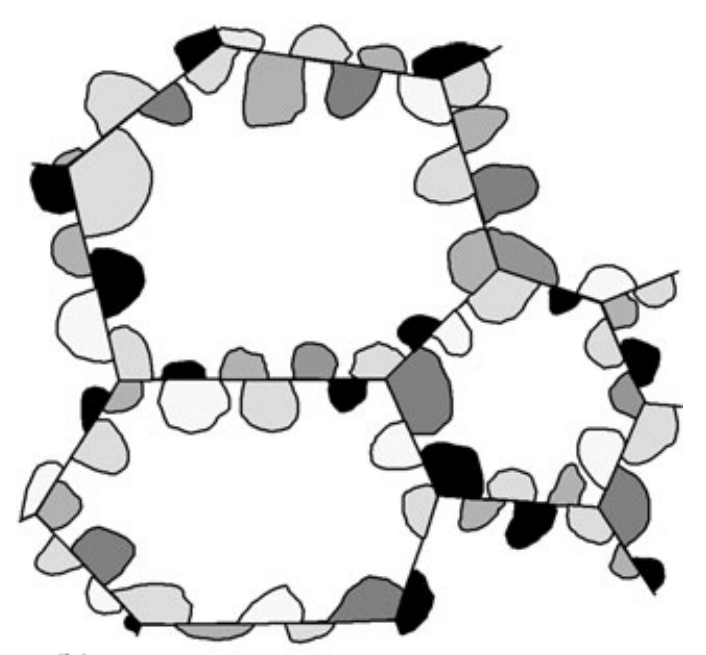

(b)

Fig. 2. Microtexture engineering through variant selection at parent grain boundaries. (a) Limiting chemical sensitivity by suppressing misorientation: one product crystal growing on both sides of the grain boundary, in OR with every parent grain. (b) Grain refinement by enhanced nucleation of highly misoriented grains of product phase.

[Ti alloy + TiB] metal matrix composite (Feng et al., 2005) and even in meteoritic minerals (Geist et al., 2005),

3. parent and product phases in discontinuous precipitation, for example, in Cu alloys (Li et al., 1994; Mangan \& Shiflet, 1997) and in Ni base alloy (Lavigne et al., 2001, 2004; Sennour et al., 2004),

4. successively deposited thin film layers, for example, on sapphire (Cain \& Lange, 1994; Cain et al., 1995; Loloee et al., 2001; Trager-Cowan et al., 2001), on polycrystalline $\mathrm{Cu}$ (Missiaen et al., 2005), on GaN (Davydov et al., 2004) and on Ti oxide (Cosandey, 1997; Cosandey et al., 2001),

5. product matrix phases formed by solid-state phase transformation (e.g. Miyamoto et al., 2003): a number of references concerning both diffusional and martensitic phase transformations in ferrous, non-ferrous and
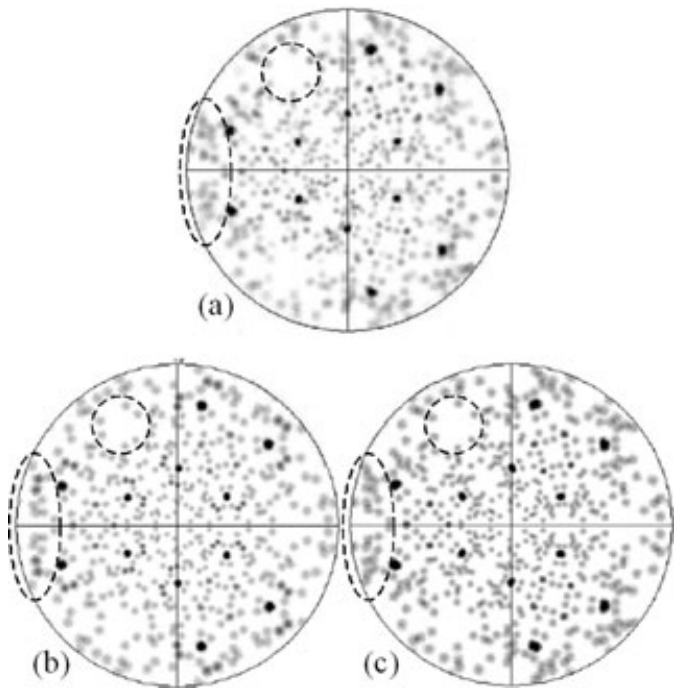

Fig. 3. $\{127\}$ pole figures of (a) a duplex steel (single austenite grain), (b) simulated ferrite variants using the classical Kurdjumov-Sachs OR, and (c) simulated ferrite variants using the OR fitted by the author. Some areas where better agreement is obtained with (c) than with (b) are underlined by dashed ellipses. After Nolze (2006).

intermetallic alloys are given in Gourgues-Lorenzon (2007).

The accuracy of the method is typically $0.5^{\circ}$. Interesting indications may be obtained using higher index pole figures, which give characteristic patterns for known ORs (Nolze, 2004, 2006; Fig. 3). To the author's knowledge, higher accuracy is not necessary for most applications: many phase transformations occur at high temperature and several phenomena can subsequently disturb the local orientation of crystals, making the OR depart from its original value before the sample can be investigated by EBSD:

1. Strain incompatibility induced by the phase transformation (due to shear and/or volume change) may locally lead to plastic deformation and rotation of the crystals, in particular if one of the phases is much harder and in much higher volume fraction than the other one. The difference in flow properties of phases may also lead to stress redistribution by plastic or viscoplastic strain. A typical example is the mechanical stabilization of retained austenite films in martensite steel microstructures. Plastic deformation also leads to internal misorientations within phases, making it difficult to retrieve the original orientation of parent or product phase, or both. Such phenomena may even occur too rapidly to be caught by in situ experiments.

2. Anisotropy and/or differences in the thermal expansion properties of phases may lead to strain incompatibility during cooling from the transformation temperature down to room temperature, again leading to plastic deformation and crystal rotation (e.g. Bouche et al., 2000). 
Even with accurate determination of crystal orientations, determination of ORs between phases is only achievable by reverse analysis of the above-mentioned effects. This implies use of crystal plasticity property data in a range of temperature and strain rate values, which are generally not available. Consequently, unless a very local property such as the structure of interphase interfaces or the orientation gradient in parent grains is to be investigated (usually by TEM), there is no need for accurate determination of ORs with accuracy higher than that given by the EBSD technique in the SEM.

\section{Microtexture development: does EBSD provide sufficiently comprehensive information?}

The EBSD technique has allowed microtexture investigation over statistically significant areas in a number of products of phase transformations, providing strong confirmation of results already obtained by TEM. However, several difficulties may still impair interpretation of results, as for example

1. Sampling effects can arise owing to two-dimensional (2D) sectioning of phases, whose morphology could be strongly related to their crystal orientation (Fig. 4). Such effects have been referred to as 'pseudo' variant selection (Cabus, 2005). They may significantly bias the results, so that all available information on phase morphology (elongated direction, habit planes) versus phase crystallography should be thoroughly searched for and mathematically used before claiming for 'true' variant selection.

2. Many phases appeared from solid-state transformation nucleate at grain boundaries of the parent phase, according to the orientation of two or three parent grains joining at the nucleation site and on the local geometry of the grain boundary, so that local characterization of the material close to the nucleation site may be difficult. The texture and microtexture of the parent phase may strongly affect variant selection during the phase transformation. In many cases, a close-packed plane of each phase is almost common, so that a fibre texture around the normal to that particular family of planes (in the parent phase)

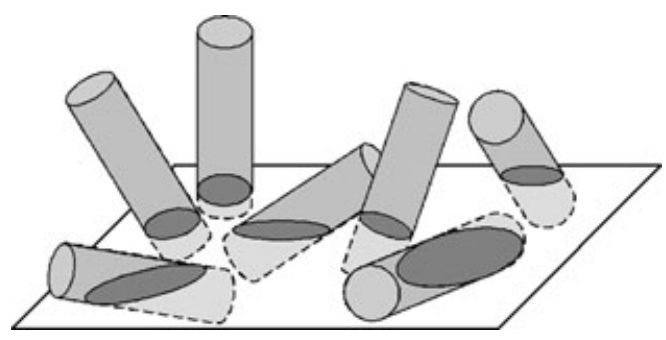

Fig. 4. Pseudo variant selection in the case of cylindrical rods elongated along a given $<\mathrm{hkl}>$ direction of the parent phase. According to the angle between (hkl) and the sample normal, apparent variant selection may be found even in the absence of true variant selection. After GourguesLorenzon (2007). favours strong variant selection. This is well documented for the $\beta$ to primary $\alpha$ transformation in titanium alloys $\left(\{0001\}_{\alpha} / /\{110\}_{\beta}\right)$ (Stanford \& Bate, 2004). This could also be the case, although still scarcely documented, for the formation of bainitic ferrite in high strength low alloy steels. As the phase transformation starts from austenite grain boundaries and goes very differently from one parent grain to the other (at least from 2D sections, see e.g. Lambert-Perlade et al., 2004), both variant selection at grain boundaries and pseudo variant selection could be expected.

\section{Present use of EBSD: some remarks}

The huge amount of data that can now be readily collected using EBSD has allowed revisiting many features of phase transformations. The EBSD technique is rather easy to use for a number of materials (in particular, for most metal alloys). However, difficult sample preparation and/or charging artefacts have to be faced for composite and ceramic materials, so that applications of EBSD are less developed for these materials than for conductive samples. Many approaches developed for metallic materials could be fruitfully extended to non-conductive and composite materials. By contrast, there is still a lack of mathematical evaluation of the statistical significance of results on a sound experimental basis for, for example, small parent grain size, that is, for grains containing a low number of daughter variants (Kitahara et al., 2005; Morito et al., 2005).

The main limitations of EBSD regarding phase transformations are (i) its still limited spatial resolution with respect of characteristic microstructural size of nanometre-sized phases and nanostructured materials, (ii) the $2 \mathrm{D}$ character of spatial information (although the full crystal orientation matrix is given), (iii) still time-consuming data acquisition, limiting in situ characterization even with rapid systems and (iv) lack of information about dislocation structures. Points (ii) and (iii), which are currently addressed in cutting-edge research, are discussed in the next section.

\section{Possible future evolutions of the EBSD technique}

As the EBSD technique has now widely spread over many materials science laboratories, including industrial facilities, there are several ways to improve data collection and processing. The most common one is to continuously improve data collection, although manual use based on operator skills or in-house calculation algorithms are still relevant tools, for example, to study composite materials with strong contrast in phase hardness (De Kloe et al., 2008) and to set up reflector tables for identification of phases in case of ambiguity in patterns (see Gourgues-Lorenzon, 2007; Zaefferer et al., 2008a). 
Table 2. Various ways to get 3D information about the microtexture of materials (see also 'uncoupled' and "coupled" methods in Table 29 as well as Table 30 from Gourgues-Lorenzon, 2007).

\begin{tabular}{|c|c|c|c|c|c|}
\hline Technique & Tools & Expected results & Advantages & Drawbacks & Examples \\
\hline $\begin{array}{l}\text { 2D EBSD + advanced } \\
\text { data processing }\end{array}$ & $\begin{array}{l}\text { EBSD + trace } \\
\text { analysis + } \\
\text { statistics } \\
\text { and/or } \\
\text { geometry }\end{array}$ & $\begin{array}{l}\text { Comprehensive } \\
\text { characterization of } \\
\text { interfaces on a } \\
\text { statistical basis }\end{array}$ & $\begin{array}{l}\text { Easily automated data } \\
\text { handling. No particular } \\
\text { experimental setup. } \\
\text { Quick, cost-effective }\end{array}$ & $\begin{array}{l}\text { Sensitive to texture. Needs } \\
\text { normalization by random } \\
\text { distributions. Provides } \\
\text { average information only }\end{array}$ & $\begin{array}{l}\text { Grain boundary } \\
\text { misorientation and } \\
\text { planes: Larsen \& } \\
\text { Adams (2004) }\end{array}$ \\
\hline $\begin{array}{l}\text { 2D EBSD }+3 \mathrm{D} \\
\text { morphological } \\
\text { investigations }\end{array}$ & $\begin{array}{c}\text { EBSD + deep } \\
\text { etching }\end{array}$ & $\begin{array}{l}\text { Connectivity of } \\
\text { phases, qualitative } \\
\text { information about } \\
\text { phase morphology }\end{array}$ & $\begin{array}{l}\text { Rather easy to use provided } \\
\text { good etchants and } \\
\text { suitable characterization } \\
\text { procedures are known }\end{array}$ & $\begin{array}{l}\text { No quantitative correlation } \\
\text { between morphology and } \\
\text { crystallography if } \\
\text { boundaries are not visible } \\
\text { in the third dimension }\end{array}$ & $\begin{array}{l}\text { Eutectic Si: Nogita \& } \\
\text { Dahle (2001a, } \\
\text { 2001b); } \\
\text { proeutectoid } \\
\text { cementite: } \\
\text { Mangan et al. } \\
\text { (1999); } \\
\text { intergranular } \\
\text { cementite: Kral \& } \\
\text { Spanos (2003); } \\
\text { eutectic carbides: } \\
\text { Randle \& Powell } \\
\text { (1993) }\end{array}$ \\
\hline $\begin{array}{l}2 \mathrm{D} \mathrm{EBSD}+3 \mathrm{D} \\
\text { morphological } \\
\text { investigations }\end{array}$ & $\begin{array}{l}\text { 2D EBSD }+ \\
\text { metallographic } \\
\text { serial sections } \\
\text { or two-plane } \\
\text { analysis }\end{array}$ & $\begin{array}{l}\text { Connectivity of } \\
\text { phases, } \\
\text { quantitative } \\
\text { information on } \\
\text { morphology }\end{array}$ & $\begin{array}{l}\text { Easier to use and much less } \\
\text { data to handle than for } \\
\text { full 3D characterization. } \\
\text { Little particular } \\
\text { experimental setup }\end{array}$ & $\begin{array}{l}\text { Tedious. Assumes that } \\
\text { morphology and } \\
\text { crystallography are } \\
\text { strongly correlated (e.g. } \\
\text { well-visible grain } \\
\text { boundaries) }\end{array}$ & $\begin{array}{l}\text { Already used for } \\
\text { grain boundary } \\
\text { characterization: } \\
\text { Randle (2004); } \\
\text { fracture analysis } \\
\text { and phase } \\
\text { transformation } \\
\text { e.g. in Ti alloys: } \\
\text { Zimmermann \& } \\
\text { Humbert (2002); } \\
\text { ferrite: Spanos } \\
\text { et al. (2005), Kral } \\
\text { \& Spanos (2005) }\end{array}$ \\
\hline $\begin{array}{l}2 \mathrm{D} \mathrm{EBSD}+3 \mathrm{D} \\
\text { morphological } \\
\text { investigations }\end{array}$ & $\begin{array}{l}\text { Crystal } \\
\text { orientation } \\
\text { mapping in } \\
\text { TEM }\end{array}$ & $\begin{array}{l}\text { Full local } \\
\text { characterization, } \\
\text { including interface } \\
\text { morphology }\end{array}$ & $\begin{array}{l}\text { High spatial resolution, } \\
\text { information about } \\
\text { dislocation structures }\end{array}$ & $\begin{array}{l}\text { Tedious sample preparation, } \\
\text { sampling effects to be } \\
\text { expected due to the very } \\
\text { local investigation scale }\end{array}$ & $\begin{array}{l}\text { Zaefferer (2000), } \\
\text { Rauch \& Dupuy } \\
(2005)\end{array}$ \\
\hline $\begin{array}{l}\text { Full 3D } \\
\text { characterization }\end{array}$ & $\begin{array}{l}\text { EBSD/metallo- } \\
\text { graphic serial } \\
\text { sections (EBSD } \\
\text { on every } \\
\text { section) }\end{array}$ & $\begin{array}{l}\text { Full 3D microtexture } \\
\text { (3D EBSD maps) }\end{array}$ & $\begin{array}{l}\text { Possibility to investigate } \\
\text { rather large samples. Does } \\
\text { not require FIB equipment }\end{array}$ & $\begin{array}{l}\text { Destructive and tedious. } \\
\text { Sample preparation and } \\
\text { alignment of images are } \\
\text { difficult. Spatial resolution } \\
\text { limited by accuracy of } \\
\text { metallographic polishing }\end{array}$ & $\begin{array}{l}\text { Martensite: } \\
\text { Rowenhorst et al. } \\
\text { (2006); pearlite: } \\
\text { Mangan \& Shiflet } \\
\text { (1999); } \\
\text { precipitation: } \\
\text { Mangan \& Shiflet } \\
\text { (1997), Lewis et al. } \\
\text { (2006) }\end{array}$ \\
\hline
\end{tabular}


Table 2.-Continued.

\begin{tabular}{|c|c|c|c|c|c|}
\hline Technique & Tools & Expected results & Advantages & Drawbacks & Examples \\
\hline $\begin{array}{l}\text { Full 3D } \\
\text { characterization }\end{array}$ & $\begin{array}{l}\text { EBSD/FIB } \\
\text { tomography }\end{array}$ & $\begin{array}{l}\text { Full 3D microtexture } \\
\text { (3D EBSD maps) }\end{array}$ & $\begin{array}{l}\text { Available in any laboratory } \\
\text { equipped with dual-beam } \\
\text { column. High spatial } \\
\text { resolution. Used even for } \\
\text { complex, deformed, } \\
\text { distorted microtextures }\end{array}$ & $\begin{array}{l}\text { Destructive. Sample } \\
\text { preparation and } \\
\text { alignment of images are } \\
\text { difficult. Dedicated to } \\
\text { small samples (typically } \\
50 \text { by } 50 \mu \mathrm{m}^{2} \text { in } \\
\text { cross-section) }\end{array}$ & $\begin{array}{l}\text { Viability of the } \\
\text { technique: } \\
\text { Mulders \& Day } \\
\text { (2005), Ferry et al. } \\
\text { (2007). } \\
\text { Solidification: } \\
\text { Henry et al. } \\
\text { (1998a), Abdul } \\
\text { Wahab et al. } \\
\text { (2006); ferrite: } \\
\text { Yokomizo et al. } \\
\text { (2003); pearlite: } \\
\text { Zaefferer et al. } \\
\text { (2008b); thin } \\
\text { films: Chen \& } \\
\text { Rudolph (2003), } \\
\text { Bastos et al. (2006) }\end{array}$ \\
\hline $\begin{array}{l}\text { Full 3D } \\
\text { characterization }\end{array}$ & $\begin{array}{l}\text { 3D XRD, 3D } \\
\text { X-ray crystal or } \\
\text { diffraction } \\
\text { contrast } \\
\text { microscopy }\end{array}$ & Full 3D microtexture & $\begin{array}{l}\text { Non-destructive, allowing in } \\
\text { situ characterization. } \\
\text { High angular resolution } \\
\left(\text { around } 0.1^{\circ} \text { ) }\right.\end{array}$ & $\begin{array}{l}\text { Needs a synchrotron source. } \\
\text { Limited spatial resolution } \\
(\sim \mu \mathrm{m}) \text {. Only for crystals } \\
\text { containing a low density } \\
\text { of defects }\end{array}$ & $\begin{array}{l}\text { Juul Jensen (2000), } \\
\text { Liu et al. (2004), } \\
\text { Ludwig et al. } \\
\text { (2008), Johnson } \\
\text { et al. (2008) }\end{array}$ \\
\hline
\end{tabular}

\section{Improving data acquisition versus improving data processing?}

Great efforts are currently made in two main areas, both bringing a third dimension to more conventional 2D data collection. This new dimension is either the sample thickness (i.e. 3D information on microtexture) or time (i.e. by in situ investigation). There are two ways to get such information; both of which are addressed in the following sections of this paper:

1. Improving data collection to directly obtain either 3D orientation maps or in situ evolution of a given area.

2. Using 'indirect' methods to get information from 2D EBSD data together with advanced data processing.

Direct collection of 3D or real-time EBSD data, increasingly allowed by high-speed EBSD systems, is still time-consuming and experimentally difficult. Up to now, it has been mostly developed for research purposes, to get deeper understanding of physical phenomena and mechanisms that govern material evolution (strain, recrystallization, phase transformation and so on).

Another way to improve the contribution of the EBSD technique to materials science and engineering is to develop large-scale, effective, cost-saving use of EBSD by introducing and automating new data processing methods or by developing simplified experimental procedures, validated against more sophisticated experiments. The mathematical background of such methods may be complex for materials scientists, who may not be familiar with advanced geometry, algebra or probability theories (see e.g. Larsen \& Adams, 2004; Saylor et al., 2004; Cayron, 2006, 2007). However, once such algorithms are implemented in the software, only crystallographic and spatial data have to be explicitly handled with. These data are already commonly processed to build and use EBSD maps.

\section{Three-dimensional microtexture of materials}

Although the EBSD technique provides the full crystal orientation matrix, one still needs 3D information about spatial location, such as phase morphology, interface geometry and so on. There are several ways, with various levels of complexity, to get such information (Table 2). Even extensively investigated microstructures such as martensite and bainite packets in steels are worth of further 3D characterization with the help of EBSD. The 2D spatial and shape distribution of variants into blocks and packets is now well characterized (Nakashima et al., 2001; Dronhofer et al., 2003; Morito et al., 2003, 2006; Furuhara et al., 2006) but what about the 3D morphology of these entities? According to $2 \mathrm{D}$ results, the grain size (i.e. size of crystals delimited with high-angle boundaries) is much finer in lath martensite than in upper bainite (Gourgues et al., 2000). However, the propagation of cleavage cracks, which generally occurs along $\{001\}$ planes, may not rely on this characteristic grain size, but on the parent austenite grain size, which may be much 


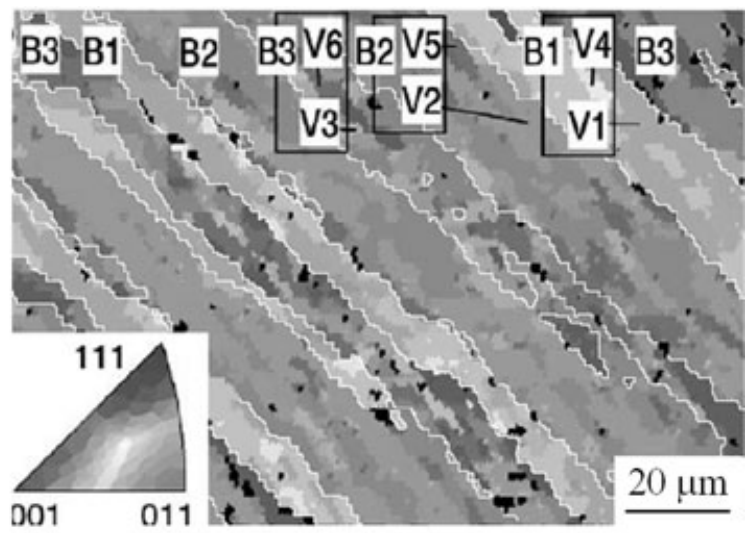

(a)

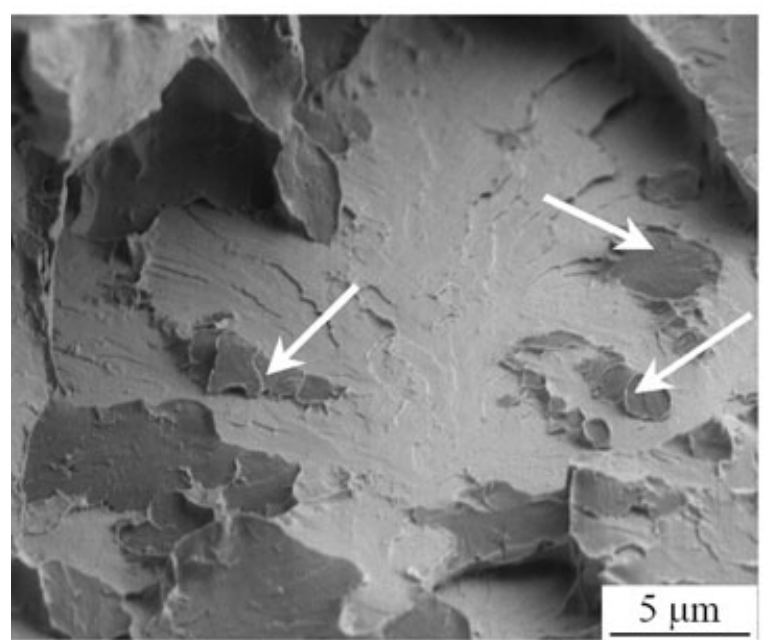

(b)

Fig. 5. Necessity of 3D determination of microtexture to characterize brittle cleavage cracking in lath martensite and lower bainitic steels. (a) EBSD map showing a high density of high-angle boundaries (in white) in a lath martensite steel, after Morito et al. (2003). (b) Cleavage facet from a lower bainitic steel, showing how the crack found favourably oriented crystal in a quasi-continuous way, after Gourgues (2003).

coarser (Fig. 5). In fact, a propagating cleavage crack may skip an unfavourably oriented crystal, provided that a continuous path of suitably oriented crystals may be found in 3D. This path is strongly influenced by the first crystals to be formed during the phase transformation. These crystals grow throughout the parent grain from one boundary to another. Here, the relevant property (resistance to cleavage crack propagation) is strongly influenced by the 3D microtexture, and not by what could be inferred from 2D EBSD mapping.

Full 3D characterization of microtextures is still under development using tomography associated with both XRD and EBSD techniques. Both are complementary in terms of spatial resolution, sample size and microstructures that can be investigated. They produce huge amounts of data from still long and experimentally tedious measurements. Such experiments are the only way to completely characterize the morphology of quantitatively defined grains, that is, crystals whose boundaries are defined using objective parameters such as a minimum misorientation angle. The 3D shape of complex transformation microstructures such as bainite and martensite packets in steels and cast irons, and colonies of $\alpha$ phase in brass and titanium alloys is still not known, but the still limited size of volumes to be investigated in 3D (typically $20 \mu \mathrm{m}$ in side) is not fully compatible with the minimum parent grain size to obtain 'typical' packets or colonies of the product phase. There is thus a need in increasing the size of volumes to be investigated by this method.

This kind of experiments could then be used together with 3D mathematical morphology models (see e.g. Groeber et al., 2006). Besides phase transformations, such experiments have already provided entry data to simulate the evolution of single crystal or polycrystalline materials, by using, for example, crystal plasticity flow rules (Zaafarani et al., 2006), damage or fracture models. Such models cannot give accurate results at a local scale if only 2D morphological data (such as from conventional 2D EBSD mapping) are used, because of first-order effects of the underlying substrate (Zeghadi et al., 2007). Alternatively, statistical properties can be derived from 3D simulations of microtextures constrained by surface observations (Saylor et al., 2004; Zeghadi et al., 2007). Comparison with 3D simulation of phase transformations by phase-field models should also give interesting results.

'Indirect' methods, associating 2D EBSD mapping and mathematically aided data processing could also be used to get average properties of the microstructure, under 'metallurgically reasonable' assumptions. An interesting example of mathematically aided EBSD data processing is given by Cayron (2007) for the case of multiple twinning: by algebraically calculating possible combinations of misorientation relationships between $\Sigma 3^{\mathrm{n}}$ variants from a given parent crystal, one may quickly and automatically reconstruct 'twin-related' domains (TRDs) from an EBSD map. Such domains may not be connected in 2D but can be connected in 3D, and the software is capable of associating several non-connected TRDs, giving some information about the 3D microtexture with no experimental and little numerical effort.

\section{In situ EBSD experiments: tracking the history of microtextures}

The retained parent phase, which can be accessed in certain conditions after interrupted phase transformation, does generally not provide sufficient information for at least two reasons:

1. As detailed earlier, constrained local deformation may have induced crystal rotation of small particles (e.g. islands or films).

2. Even if local deformation is negligible, not all crystal orientations may have been retained, some being 
Table 3. Various ways to track history of the microtexture of materials with the help of EBSD.

\begin{tabular}{|c|c|c|c|c|c|}
\hline Technique & Tools & Expected results & Advantages & Drawbacks & Examples \\
\hline $\begin{array}{l}\text { Conventional } \\
\text { EBSD }+ \\
\text { advanced } \\
\text { data } \\
\text { processing }\end{array}$ & $\begin{array}{l}\text { EBSD + algebraic } \\
\text { calculations } \\
\text { from } \\
\text { misorientation } \\
\text { between } \\
\text { product } \\
\text { crystals }\end{array}$ & $\begin{array}{l}\text { Microtexture of } \\
\text { parent phase vs. } \\
\text { microtexture of } \\
\text { product phases }\end{array}$ & $\begin{array}{l}\text { No particular experimental } \\
\text { set-up. Easy, rapid and } \\
\text { cost-effective once } \\
\text { implemented in software }\end{array}$ & $\begin{array}{l}\text { Needs several variants to retrieve } \\
\text { parent crystal orientation (up to } \\
4 \text { for bcc to hcp phase } \\
\text { transformation). Ambiguity still } \\
\text { found if product phase in OR with } \\
\text { several parent grains }\end{array}$ & $\begin{array}{l}\text { Ti alloys: Humbert } \\
\text { et al. (1994), } \\
\text { Glavicic et al. } \\
\text { (2004b), Cayron } \\
\text { (2006), Germain } \\
\text { et al. (2007) }\end{array}$ \\
\hline $\begin{array}{l}\text { Conventional } \\
\text { EBSD }+ \text { in } \\
\text { situ } \\
\text { imaging }\end{array}$ & $\begin{array}{l}\text { EBSD in initial } \\
\text { and final states. } \\
\text { In situ } \\
\text { microscopy } \\
\text { (not } \\
\text { necessarily in a } \\
\text { SEM) }\end{array}$ & $\begin{array}{l}\text { Tracking the history } \\
\text { of crystal } \\
\text { morphology. Link } \\
\text { to local } \\
\text { crystallography } \\
\text { (e.g. nucleation at } \\
\text { particular sites, } \\
\text { growth directions) }\end{array}$ & $\begin{array}{l}\text { No particular requirement for } \\
\text { experimental EBSD set-up }\end{array}$ & $\begin{array}{l}\text { For one phase transformation only } \\
\text { (e.g. no grain growth); surface } \\
\text { artefacts to be expected }\end{array}$ & $\begin{array}{l}\text { Cu-Al-Be alloy: } \\
\text { Kaouache } \text { et al. } \\
\text { (2004); Fe alloys: } \\
\text { Phelan \& } \\
\text { Dippenaar (2004), } \\
\text { Ueda et al. (2004), } \\
\text { Watanabe et al. } \\
\text { (2004, 2005), } \\
\text { Phelan et al. } \\
\text { (2005), Nagashio } \\
\text { et al. (2004); Si: } \\
\text { Nagashio \& } \\
\text { Kuribayashi } \\
\text { (2006) }\end{array}$ \\
\hline $\begin{array}{l}\text { In situ EBSD } \\
\text { and SEM } \\
\text { imaging }\end{array}$ & $\begin{array}{l}\text { 'Hot' stage fitted } \\
\text { to EBSD (e.g. } \\
\text { tilted electron } \\
\text { column) or } \\
\text { EBSD fitted to } \\
\text { hot stage }\end{array}$ & $\begin{array}{l}\text { Quasi-continuous } \\
\text { information on } \\
\text { microtexture } \\
\text { during the phase } \\
\text { transformation }\end{array}$ & $\begin{array}{l}\text { Full characterization of the } \\
\text { history of microtexture }\end{array}$ & $\begin{array}{l}\text { Temperature or mechanical loading } \\
\text { control may be difficult; surface } \\
\text { artefacts to be expected }\end{array}$ & $\begin{array}{l}\text { Titanium: Seward } \\
\text { et al. (2004); } \\
\text { cobalt: Wright } \\
\text { et al. (2005); iron } \\
\text { oxides: Piazolo } \\
\text { et al. (2004) }\end{array}$ \\
\hline
\end{tabular}

transformed more easily than others. This is typically the case in phase transformation of austenite in steels (Field et al., 1996).

As for 3D investigations, there are several methods to combine EBSD data with real-time characterization of phase transformations to get a piece of history of the product microstructure. They are schematically depicted in Table 3, following the same classification as in Table 2. Of course, the most sophisticated and most direct one is repeated EBSD mapping during the experiment in the SEM (in situ EBSD). Such experiments strongly rely on the ability of modern EBSD systems to rapidly acquire maps, in a secondary or in a partial vacuum. One could even imagine using simultaneously some non-destructive bulk characterization method to monitor phase transformation in the whole sample, as is currently done with magnetization or potential drop measurements outside the SEM. This would allow comparing in situ characterization of the sample surface (with EBSD) with values from the bulk of the sample, to assess possible surface effects.

An intermediate way is to combine a few EBSD investigations (e.g. of initial and final states) with in situ observations (see Table 3). Alternatively, developing approaches, which can also be useful to master variant selection, and thus microstructural engineering use advanced mathematical methods to improve EBSD data processing. They have been applied using either matrix calculations or even algebraic theories (Cayron, 2006) to infer the microtexture of the parent phase from that of the product phase. Parent phase reconstruction is now possible from 2D EBSD maps (Gey \& Humbert, 2003; Glavicic et al., 2003a,b, 2004a,b; Germain et al., 2004, 2007; Cayron et al., 2006). This could be extended to $3 \mathrm{D}$ considerations.

\section{Concluding remarks}

With the continuous development of both data collection and data processing methods, the EBSD technique will probably still be increasingly used to investigate microstructures as products of phase transformations. Until now, EBSD has mainly been used as a characterization technique, to 'revisit' results already acquired by other techniques but on a sound statistical basis that cannot generally be achieved by TEM. Besides extensive characterization, 'medium-scale' modelling approaches using micromechanics or even phase field 
simulation should be coupled to EBSD results in order to get from descriptive models to prediction tools. The development of such methods would lead to an improvement in properties related to the local and medium-scale microtexture, such as toughness and strengthening through a high number density of high-angle boundaries. The average texture could also be improved, leading to better-controlled anisotropy and, for example, better forming properties.

Going into full 3D considerations and tracking phase history will bring EBSD into part of a toolbox, connected to microstructural modelling (by e.g. micromechanical or phase field models) devoted to both deeper understanding of physical mechanisms and tailoring of resulting microtextures. There are several ways to this, from the most sophisticated ones to the simplest, cost-effective ones. All are complementary to each other, enabling much progress for the increasing variety of EBSD users in the materials science and engineering community.

\section{Acknowledgements}

One of the referees is gratefully acknowledged for his or her thorough reading and many suggestions that have greatly contributed to the final version of this paper.

\section{References}

Abdul Wahab, A., Hutchinson, C.R. \& Kral, M.V. (2006) A threedimensional characterization of creep void formation in hydrogen reformer tubes. Scr. Mater. 55, 69-73.

Abdul Wahab, A. \& Kral, M.V. (2005) Three dimensional analysis of creep voids. Microsc. Microanal. 2 (11 Suppl.), 224-225.

Adachi, Y. \& Tsuzaki, K. (2005) Coherent to incoherent transition of intergranular bcc-precipitates by pre-/post deformations in a $\mathrm{Ni}-43 \mathrm{Cr}$ alloy. ISIJ Int. 45, 1703-1710.

Adachi, Y., Hakata, K. \& Tsuzaki, K. (2005) Crystallographic analysis of grain boundary Bcc-precipitates in a Ni-Cr alloy by FESEM/EBSD and TEM/Kikuchi line methods. Mater. Sci. Eng. A412, 252-263.

Ardakani, M.G., D’Souza, N., Shollock, B.A. \& McLean, M. (2000) Directional and single-crystal solidification of Ni-base superalloys: Part II. Coincidence site lattice character of grain boundaries. Metall. Mater. Trans. 31A, 2887-2893.

Baba-Kishi, K.Z. (2002) Review: electron backscatter Kikuchi diffraction in the scanning electron microscope for crystallographic analysis. J. Mater. Sci. 37, 1715-1746.

Banerjee, R., Bhattacharyya, D., Collins, P.C., Viswanathan, G.B. \& Fraser, H.L. (2004) Precipitation of grain boundary a in a laser deposited compositionally graded Ti-8Al-xV alloy-an orientation microscopy study. Acta Mater. 52, 377-385.

Bastos, A., Zaefferer, S., Raabe, D. \& Schuh, C. (2006) Characterization of the microstructure and texture of nanostructured electrodeposited NiCo using electron backscatter diffraction (EBSD). Acta Mater. 54, 2451-2462.

Bezençon, C., Schnell, A.\& Kurz, W. (2003) Epitaxial deposition of MCrAlY coatings on a Ni-base superalloy by laser cladding. Scr. Mater. 49, 705709 .
Bhattacharyya, D., Viswanathan, G.B., Denkenberger, R., Furrer, D. \& Fraser, H.L. (2003) The role of crystallographic and geometrical relationships between $\alpha$ and $\beta$ phases in a $\alpha / \beta$ titanium alloy. Acta Mater. 51, 4679-4691.

Boehlert, C.J., Civelekoglu, S., Gundakaram, R.C. \& Bingert, J.F. (2004) The grain boundary character distribution in $\mathrm{BCC}$ and $\mathrm{O}+\mathrm{BCC} \mathrm{Ti}-\mathrm{Al}-\mathrm{Nb}$ alloy microstructures. Proc. Ti-2003 Science and Technology (ed. by G. Lütjering \& J. Albrecht), vol. 4, pp. 2145-2152. Wiley-VCH, Weinheim, Germany.

Bouche, G., Béchade, J.L., Mathon, M.H., Allais, L., Gourgues, A.F. \& Naźe, L. (2000) Texture of welded joints of 316L stainless steel, multi-scale orientation analysis of a weld metal deposit. J. Nucl. Mater. 277, 91-98.

Brooks, J.A. Robino, C.V., Headley, T.J. \& Michael, J.R. (2003) Weld solidification and cracking behavior of free-machining stainless steel. Weld. J. 82, 51S-64S.

Cabus, C. (2005) Study and modelling of phase transformation textures in drawing steels. PhD dissertation, University Paris 13 (in French).

Cain, M.G. \& Lange, F.F. (1994) Heteroepitaxy of cubic zirconia on basal and prismatic planes of sapphire. J. Mater. Res. 9, 674-687.

Cain, M.G., Lange, F.F., Lewis, M.H. \& Bjorkert, S. (1995) Substrate and fibre coatings form aqueous, zirconia-based liquid precursors. Proc. Novel Synthesis and Processing of Ceramics (ed. by F.R. Sale), pp. 7-31. The Institute of Materials, London.

Cayron, C. (2006) Groupoid of orientational variants. Acta Cryst. A62, 21-40.

Cayron, C., Artaud, B. \& Briottet, L. (2006) Reconstruction of parent grains from EBSD data. Mater. Charact. 57, 386-401.

Cayron, C. (2007) Multiple twinning in cubic crystals: geometric/ algebraic study and its application for the identification of the $\Sigma 3^{\text {n }}$ grain boundaries. Acta Cryst. A63, 11-29.

Chen, H.-W. \& Rudolph, V. (2003) The 3-D structure of polycrystalline diamond film by electron backscattering diffraction (EBSD). Diam. Relat. Mater. 12, 1633-1639.

Cosandey, F. (1997) High spatial resolution EBSD study of nanosized epitaxial particles. Microsc. Microanal. 3, 559-560.

Cosandey, F., Zhang, L. \& Madey, T.E. (2001) Effect of substrate temperature on the epitaxial growth of $\mathrm{Au}$ on $\mathrm{TiO}_{2}$ (110). Surf. Sci. $474,1-13$.

Davies, P.S., Croft, R.M.J., Wynne, B.P., Rainforth, W.M. \& Threadgill, P. (2008) An investigation of microstructural evolution in titanium friction stir welds using electron back scatter diffraction. Fifteenth EBSD Meeting (ed. by B. Wynne), (abstract only). Royal Microscopical Society, Oxford.

Davydov, A.V., Bendersky, L.A., Boettinger, W.J., Josell, O., Vaudin, M.D., Chang, K.-S. \& Takeachi, I. (2004) Combinatorial investigation of structural quality of Au/Ni contacts on GaN. Appl. Surf. Sci. 223, 24-29.

De Kloe, R., Wright, S. \& Nowell, M. (2008) Interactive EBSD analysis of fatigue crack planes. Fifteenth EBSD Meeting (ed. by B. Wynne), (abstract only). Royal Microscopical Society, Oxford.

Dingley, D.J. \& Baba-Kishi, K. (1986) Use of electron back scatter diffraction patterns for determination of crystal symmetry elements. Proc. Scanning Electron Microscopy (ed. by O. Johari), vol. II, pp. 383391. SEM Inc., Chicago, IL.

Dingley, D.J. \& Randle, V. (1992) Review-Microtexture determination by electron back-scatter diffraction. J. Mater. Sci. 27, 45454566 .

Dingley, D. (2004) Progressive steps in the development of electron backscatter diffraction and orientation imaging microscopy. J. Microsc. 213, 214-224. 
Dronhofer, A., Pešicka, J., Dlouhý, A. \& Eggeler, G. (2003) On the nature of internal interfaces in tempered martensite ferritic steels. Z. Metallkd. 94, 511-520.

D’Souza, N., Ardakani, M.G., McLean, M. \& Shollock, B.A. (2000) Directional and single-crystal solidification of Ni-base superalloys: Part I. The role of curved isotherms on grain selection. Metall. Mater. Trans. 31A, 2877-2886.

Feng, H., Zhou, Y., Jia, D. \& Meng, Q. (2005) Microstructural characterization of spark plasma sintered in situ TiB reinforced Ti matrix composite by EBSD and TEM. Mater. Trans. 46, 575-580.

Ferry, M., Xu, W., Mateescu, N., Cairney, J.M. \& Humphreys, F.J. (2007) On the viability of FIB tomography for generating 3-D orientation maps in deformed and annealed metals. Mater. Sci. Forum 550, 55-64.

Field, D.P., Wright, S.I. \& Dingley, D.J. (1996) Multi-phase texture analysis by orientation imaging microscopy. Proceedings of Eleventh International Conference on Textures of Materials ICOTOM-11 (ed. by Z. Liang, L. Zuo \& Y. Chu), pp. 94-99. International Academic Publishers, Beijing.

Furuhara, T., Kawata, H., Morito, S. \& Maki, T. (2006) Crystallography of upper bainite in Fe-Ni-C alloy. Mater. Sci. Eng. A431, 228-236.

Gandin, C.-A., Rappaz, M., West, D. \& Adams, B.L. (1995) Grain texture evolution during the columnar growth of dendritic alloys. Metall. Mater. Trans. 26A, 1543-1551.

Gäumann, M., Henry, S., Cléton, F., Wagnière, J.D. \& Kurg, W. (1999) Epitaxial laser metal forming: analysis of microstructure formation. Mater. Sci. Eng. A271, 232-241.

Geist, V., Wagner, G., Nolze, G. \& Moretzki, O. (2005) Investigations of the meteoritic mineral $(\mathrm{Fe}, \mathrm{Ni})_{3} \mathrm{P}$. Cryst. Res. Technol. 40, 52-64.

Germain, L., Gey, N., Humbert, M., Bocher, P. \& Jahazi, M. (2004) Texture and microtexture analysis of an IMI 834 alloy after thermo-mechanical processing. Proc. Ti-2003 Science and Technology (ed. by G. Lütjering \& J. Albrecht), vol. 4, pp. 1291-1298. Wiley-VCH, Weinheim, Germany.

Germain, L., Gey, N., Humbert, M., et al. (2005) Analysis of sharp microtexture heterogeneities in a bimodal IMI 834 billet. Acta Mater. 53, 3535-3543.

Germain, L., Gey, N. \& Humbert, M. (2007) Reliability of reconstructed $\beta$-orientation maps in titanium alloys. Ultramicroscopy 107, 11291135 .

Gey, N. \& Humbert, M. (2002) Characterization of the variant selection occurring during the $\alpha \rightarrow \beta \rightarrow \alpha$ phase transformations of a cold rolled titanium sheet. Acta Mater. 50, 277-287.

Gey, N. \& Humbert, M. (2003) Specific analysis of EBSD data to study the texture inheritance due to the $\beta \rightarrow \alpha$ phase transformation. J. Mater. Sci. 38, 1289-1294.

Glavicic, M.G., Kobryn, P.A., Bieler, T.R. \& Semiatin, S.L. (2003a) An automated method to determine the orientation of the hightemperature beta phase from measured EBSD data for the lowtemperature alpha phase in Ti-6Al-4V. Mater. Sci. Eng. A351, 258264.

Glavicic, M.G., Kobryn, P.A., Bieler, T.R. \& Semiatin, S.L. (2003b) A method to determine the orientation of the high-temperature beta phase from measured EBSD data for the low-temperature alpha phase in Ti-6Al-4V. Mater. Sci. Eng. A346, 50-59.

Glavicic, M.G., Kobryn, P.A., Goetz, R.L., Ya, K.O. \& Semiatin, S.L. (2004a) Texture evolution during primary processing of productionscale vacuum arc remelted ingots of Ti-6Al-4V. Proc. Ti-2003 Science and Technology (ed. by G. Lütjering, J. Albrecht), vol. 4, pp. 12991306. Wiley-VCH, Weinheim, Germany.
Glavicic, M.G., Kobryn, P.A. \& Semiatin, S.L. (2004b) Validation of an automated EBSD method to deduce the b-phase texture in Ti-6Al-4V with a colony-a microstructure. Mater. Sci. Eng. A385, 372-376.

Godet, S., Jacques, P.J., Szpunar, J.A., Jones, J.J. \& Delemay, F. (2001) Microtextural analysis of the variant selection phenomenon during the bainitic transformation. Rev. Met. (Journées d'Automne), 62 (in French).

Godet, S., Glez, J.C., He, J., Jones, J.J. \& Jacques, P.J. (2004) Grain-scale characterization of transformation textures. J. Appl. Crystallogr. 37, $417-425$.

Gourgues, A.F., Flower, H.M. \& Lindley, T.C. (2000) Electron backscattering diffraction study of acicular ferrite, bainite and martensite steel microstructures. Mater. Sci. Technol. 16, 26-40.

Gourgues, A.F. (2003) Microtexture induced by the bainitic transformation in steels during welding. Effect on the resistance to cleavage cracking. Mater. Sci. Forum 426-432, 3629-3634.

Gourgues-Lorenzon, A.F. (2007) Application of electron backscatter diffraction to the study of phase transformations. Int. Mater. Rev. 52, 65-128.

Groeber, M.A., Haley, B.K., Uchic, M.D., Dimiduk, D.M. \& Gosh, S. (2006) 3D reconstruction and characterization of polycrystalline microstructures using a FIB-EBSD system. Mater. Charact. 57, 259273.

Hase, K., Garcia-Mateo, C. \& Bhadeshia, H.K.D.H. (2004) Bainite formation influenced by large stress. Mater. Sci. Technol. 20, 14991505.

Henry, S., Jarry, P. \& Rappaz, M. (1998a) <110> dendrite growth in aluminum feathery grains. Metall. Mater. Trans. 29A, 2807-2817.

Henry, S., Minghetti, T. \& Rappaz, M. (1998b). Dendrite growth morphologies in aluminum alloys. Acta Mater. 46, 6431-6443.

Hong, H.U., Rho, B.S. \& Nam, S.W. (2001) Correlation of the $\mathrm{M}_{23} \mathrm{C}_{6}$ precipitation morphology with grain boundary characteristics in austenitic stainless steel. Mater. Sci. Eng. A318, 285-292.

Humbert, M., Moustahfid, H., Wagner, F. \& Philippe, M.J. (1994) Evaluation of the high temperature texture of the $\beta$ phase of a TA6V sample from the individual orientations of grains of the low temperature $\alpha$ phase. Scr. Metall. Mater. 30, 577-582.

Humphreys, F.J. (1999) Determination of microtexture by EBSD at high spatial resolution in a FEGSEM. Proceedings of 12th International Conference on Textures of Materials ICOTOM-12 (ed. by J.A. Szpunar), pp. 74-78. NRC Research Press, Ottawa, Canada.

Humphreys, F.J. (2004) Characterisation of fine-scale microstructures by electron backscatter diffraction (EBSD). Scr. Mater. 51, 771-776.

Hunter, A. \& Ferry, M. (2002a) Texture enhancement by inoculation during casting of ferritic stainless steel strip. Metall. Mater. Trans. 33A, 1499-1507.

Hunter, A. \& Ferry, M. (2002b) Evolution of microstructure and texture during casting of AISI 304 stainless steel strip. Metall. Mater. Trans. 33A, 3747-3754.

Iamboliev, T., Katayama, S. \& Matsunawa, A. (2003) Interpretation of phase formation in austenitic stainless steel welds. Weld. J. (December), 337S-347S.

Johnson, G., King, A., Hönnicke, M.G., Marrow, J. \& Ludwig, W. (2008) $\mathrm{X}$-ray diffraction contrast tomography: a novel technique for threedimensional grain mapping of polycrystals. II. The combined case. J. Appl. Cryst. 41, 310-318.

Juul Jensen, D. (2000) Three-dimensional orientation imaging. Electron backscatter diffraction in materials science (ed. by A.J. Schwartz, M. Kumar \& B.L. Adams), pp. 91-104. Kluwer Academic/Plenum Publishers, New York. 
Kaouache, B., Berveiller, S., Inal, K., Eberhardt, A. \& Patoor, E. (2004) Stress analysis of martensitic transformation in Cu-Al-Be polycrystalline and single-crystalline shape memory alloy. Mater. Sci. Eng. A378, 232-237.

Katayama, S., Matsunawa, A. \& Iamboliev, T. (1999) Formation mechanism of rapidly quenched microstructure of laser welds metals in austenitic stainless steels. Proceedings of 5th Conference on Trends in Welding Research (ed. by J.M. Vitek, S.A. David, J.A. Johnson, H.B. Smartt \& T. DebRoy), pp. 93-98. ASM International, Materials Park, $\mathrm{OH}$.

Kitahara, H., Ueji, R., Ueda, M., Tsuji, N. \& Minamino, Y. (2005) Crystallographic analysis of plate martensite in Fe-28.5at.\% Ni by FE-SEM/EBSD. Mater. Charact. 54, 378-386.

Kostrivas, A.D. \& Lippold, J.C. (2004) Simulating weld-fusion boundary microstructures in aluminum alloys. J. Met. 56 (February), 65-72.

Kral, M.V. \& Spanos, G. (2003) Crystallography of grain boundary cementite dendrites. Acta Mater. 51, 301-311.

Kral, M.V. \& Spanos, G. (2005) Three-dimensional analysis and classification of grain-boundary-nucleated proeutectoid ferrite precipitates. Metall. Mater. Trans. 36A, 1199-1207.

Lambert-Perlade, A., Gourgues, A.F. \& Pineau, A. (2004) Austenite to bainite phase transformation in the heat-affected zone of a high strength low alloy steel. Acta Mater. 52, 2337-2348.

Larsen, R.J. \& Adams, B.L. (2004) New stereology for the recovery of grain-boundary plane distributions in the crystal frame. Metall. Mater. Trans. 35A, 1991-1998.

Lavigne, O., Ramusat, C., Caron, P., Boivon, D. \& Pouchou, J.L. (2001) Application of EBSD analysis to the study of microstructural instabilities in single crystal superalloys. Rev. Met. (Special issue on Journées d'Automne), 140.

Lavigne, O., Ramusat, C., Drawin, S., Caron, P., Boivon, D. \& Pouchou, J.L. (2004) Relationships between microstructural instabilities and mechanical behaviour in new generation nickelbased single crystal superalloys. Proc. Superalloys 2004 (ed. by K.A. Green, T.M. Pollock, H. Harada, T.E. Howson, R.C. Reed, J.J. Schirra \& S. Walston), pp. 667-675. TMS, Warrendale, PA.

Lee, S.Y., Chun, Y.B., Han, J.W. \& Hwang, S.K. (2003) Effect of thermomechanical processing on grain boundary characteristics in two-phase brass. Mater. Sci. Eng. A363, 307-315.

Lewis, A.C., Bingert, J.F., Rowenhorst, D.J., Gupta, A., Geltmacher, A.B. \& Spanos, G. (2006) Two- and three-dimensional microstructural characterization of a super-austenitic stainless steel. Mater. Sci. Eng. A418, 11-18.

Li, J., He, Z., Saimoto, S. \& Sang, H. (1994) Anomalous transformation behaviour of off-eutectic $\mathrm{Cu}-\mathrm{Ag}$ near the eutectic temperature. Proc. Solid-Solid Phase Transformations (ed. by W.C. Johnson, J.M. Howe, D.E. Laughlin \& W.A. Soffa), pp. 195-200. TMS, Warrendale, PA.

Li, D., Wright, S.I. \& Boehlert, C.J. (2004). The grain boundary character distribution of a fully-orthorhombic Ti-25Al-24Nb(at.\%) alloy. Scr. Mater. 51, 545-550.

Li, D. \& Boehlert, C.J. (2005) Processing effects on the grain-boundary character distribution of the orthorhombic phase in Ti-Al-Nb alloys. Metall. Mater. Trans. 36A, 2569-2584.

Liu, W., Ice, G.E., Larson, B.C., Yang, W., Tischler, J.Z. \& Budai, J.D. (2004) The three-dimensional X-ray crystal microscope: a new tool for materials characterization. Metall. Mater. Trans. 35A, 1963-1967.

Loloee, R., Pratt, W.P., Jr. \& Crimp, M.A. (2001) Crystallographic characterization of sputter-deposited epitaxial $\mathrm{Nb}-\mathrm{Cu}-\mathrm{Co}$ and $\mathrm{Nb}-\mathrm{Cu}-$
Permalloy multilayers using electron back-scatter diffraction patterns. Philos. Mag. 81, 261-273.

Ludwig, W., Schmidt, S., Lauridsen, E.M., et al. (2008) X-ray diffraction contrast tomography: a novel technique for three-dimensional grain mapping of polycrystals. I. Direct beam case. J. Appl. Cryst. 41, 302309.

Mangan, M.A. \& Shiflet, G.J. (1997) Three dimensional investigation of $\mathrm{Cu}-\mathrm{Ti}$ discontinuous precipitation. Scr. Mater. 37, 517-522.

Mangan, M.A. \& Shiflet, G.J. (1999) The Pitsch-Petch orientation relationship in ferrous pearlite at small undercooling. Metall. Mater. Trans. 30A, 2767-2781.

Mangan, M.A., Kral, M.V. \& Spanos, G. (1999) Correlation between the crystallography and morphology of proeutectoid Widmanstätten cementite precipitates. Acta Mater. 47, 4263-4274.

Mason, T.A. \& Adams, B.L. (1994) The application of orientation imaging microscopy. J. Met. 46 (October), 43-45.

Matsuoka, S., Sakata, K., Furukimi, O. \& Obera, T. (1999) Orientational morphology of low carbon steel rolled in nonrecrystallized austenite region. Proc. Solid-Solid Phase Transformations'99 (ed. by M. Koiwa, K. Otsuka \& T. Miyazaki), pp. 1537-1540. The Japan Institute of Metals, Sendai.

Michael, J.R. \& Goehner, R.P. (1993) Crystallographic phase identification in the scanning electron microscope: backscattered electron Kikuchi patterns imaged with a CCD-based detector. MAS Bull. 23, 168-175.

Michael, J.R. \& Eades, J.A. (2000) Use of reciprocal lattice layer spacing in electron backscatter diffraction pattern analysis. Ultramicroscopy $\mathbf{8 1}$, 67-81.

Missiaen, J.M., Voytovych, R., Gilles, B. \& Eustathopoulos, N. (2005) Solid state spreading in the $\mathrm{Cu} / \mathrm{Cu}$ system. J. Mater. Sci. 40, 2377-2381.

Miyamoto, G., Shinyoshi, T., Yamaguchi, J., Furuhara, T., Maki, T. \& Uemori, R. (2003) Crystallography of intragranular ferrite formed on $(\mathrm{MnS}+\mathrm{V}(\mathrm{C}, \mathrm{N}))$ complex precipitate in austenite. Scr. Mater. 48, 371377.

Morito, S., Huang, X., Furuhara, T., Maki, T. \& Hansen, N. (2006) The morphology and crystallography of lath martensite in alloy steels. Acta Mater. 54, 5323-5331.

Morito, S., Saito, H., Ogawa, T., Furuhara, T. \& Maki, T. (2005) Effect of austenite grain size on the morphology and crystallography of lath martensite in low carbon steels. ISIJ Int. 45, 91-94.

Morito, S., Tanaka, H., Konishi, R., Furuhara, T. \& Maki, T. (2003) The morphology and crystallography of lath martensite in Fe-C alloys. Acta Mater. 51, 1789-1799.

Mulders, J.J.L. \& Day, A.P. (2005) Three-dimensional texture analysis. Mater. Sci. Forum 495-497, 237-244.

Nagashio, K., Murata, H. \& Kuribayashi, K. (2004) Spreading and solidification behavior of molten Si droplets impinging on substrates. Acta Mater. 52, 5295-5301.

Nagashio, K. \& Kuribayashi, K. (2005) Growth mechanism of twin-related and twin-free facet Si dendrites. Acta Mater. 53, 3021-3029.

Nagashio, K. \& Kuribayashi, K. (2006) Experimental verification of ribbon formation process in chill-block melt spinning. Acta Mater. 54, 23532360.

Nakashima, H., Terada, D., Yoshida, F., HayaKaura, H. \& Abe, H. (2001). EBSP analysis of modified 9Cr-1Mo martensitic steel. ISIJ Int. 41 (Supplement), S97-S100.

Nelson, T.W., Lippold, J.C. \& Mills, M.J. (1999a) A fundamental investigation of the evolution of boundaries and interfaces along the fusion boundary in dissimilar metal welds. Proceedings of 5 th Conference on Trends in Welding Research (ed. by J.M. Vitek, S.A. 
David, J.A. Johnson, H.B. Smartt \& T. DebRoy), pp. 221-226. ASM International, Materials Park, $\mathrm{OH}$.

Nelson, T.W., Lippold, J.C. \& Mills, M.J. (1999b) Nature and evolution of the fusion boundary in ferritic-austenitic dissimilar weld metals, Part 1: nucleation and growth. Weld. Res. Suppl. (October), 329-s-337-s.

Nogita, K. \& Dahle, A.K. (2001a) Determination of eutectic solidification mode in Sr-modified hypoeutectic Al-Si alloys by EBSD. Mater. Trans. 42, 207-214.

Nogita, K. \& Dahle, A.K. (2001b) Eutectic growth mode in strontium, antimony and phosphorus modified hypoeutectic Al-Si foundry alloys. Mater. Trans. 42, 393-396.

Nolze, G. (2004) Characterization of the fcc/bcc orientation relationship by EBSD using pole figures and variants. Z. Metallkd. 95, 744755.

Nolze, G. (2006) Improved determination of fcc/bcc orientation relationships by use of high-indexed pole figures. Cryst. Res. Technol. $41,72-77$.

Phelan, D. \& Dippenaar, R. (2004) Widmanstätten ferrite plate formation in low-carbon steels. Metall. Mater. Trans. 35A, 3701-3706.

Phelan, D., Stanford, N. \& Dippenaar, R. (2005) In situ observations of Widmanstätten ferrite formation in a low-carbon steel. Mater. Sci. Eng. A407, 127-134.

Piazolo, S., Seward, G.G.E., Seaton, N. \& Prior, O.J. (2004) The potential of combined in-situ heating experiments and detailed EBSD analysis in the investigation of grain scale processes such as recrystallization and phase transformation. Mater. Sci. Forum 467-470, 14071412 .

Randle, V. (1994) Application of electron backscatter diffraction to steel products. Ironmak. Steelmak. 21, 209-214.

Randle, V. (2004) Application of electron backscatter diffraction to grain boundary characterisation. Int. Mater. Rev. 49, 1-11.

Randle, V. \& Powell, G.L.F. (1993) Application of electron backscatter diffraction to orientation measurements of individual carbides in a white cast iron. J. Mater. Sci. Lett. 12, 779-781.

Rauch, E.F. \& Dupuy, L. (2005) Rapid spot diffraction patterns identification through template matching. Arch. Metall. Mater. 50, 8799.

Robino, C.V., Michael, J.R., Stephens, J.J., Dufont, J.N., Williams, D.B. \& Mizia, R.E. (2003) Solidification and weldability of gadoliniumcontaining nickel-based alloys. Proceedings of 6th Conference on Trends in Welding Research (ed. by S.A. David, T. DebRoy, J.C. Lippold, H.B. Smartt \& J.M. Vitek), pp. 627-632. ASM International, Materials Park, $\mathrm{OH}$

Rowenhorst, D.J., Gupta, A., Feng, C.R. \& Spanos, G. (2006) 3D crystallographic and morphological analysis of coarse martensite: combining EBSD and serial sectioning. Scr. Mater. 55, 11-16.

Saylor, D.M., Fridy, J., El-Dasher, B.S., Jung, K.Y. \& Rollett, A.D. (2004) Statistically representative three-dimensional microstructures based on orthogonal observation sections. Metall. Mater. Trans. 35A, 19691979.

Schwarzer, R.A., Singh, A.K. \& Sukkau, J. (2000) Discrimination and mapping of phase distributions by automated crystal orientation measurement. Mater. Sci. Technol. 16, 1389-1392.

Sémoroz, A., Strezov, L. \& Rappaz, M. (2002) Orientation domains and texture in hot-dipped galvanized coatings. Metall. Mater. Trans. 33A, 2695-2701.

Sennour, M., Jouneau, P.H. \& Esnouf, C. (2004) TEM and EBSD investigation of continuous and discontinuous precipitation of $\mathrm{CrN}$ in nitrided pure Fe-Cr alloys. J. Mater. Sci. 39, 4521-4531.
Seward, G.G.E., Celotto, S., Prior, D.J., Wheeler, J. \& Pond, R.C. (2004) In situ SEM-EBSD observations of the hcp to bcc phase transformation in commercially pure titanium. Acta Mater. 52, 821-832.

Small, J.A. \& Michael, J.R. (2001) Phase identification of individual crystalline particles by electron backscatter diffraction. J. Microsc. 201, 59-69.

Spanos, G., Wilson, A.W. \& Kral, M.V. (2005) New insights into the Widmanstätten proeutectoid ferrite transformation: integration of crystallographic and three-dimensional morphological observations. Metall. Mater. Trans. 36A, 1209-1218.

Stanford, N. \& Bate, P.S. (2004) Crystallographic variant selection in Ti-6Al-4V. Acta Mater. 52, 5215-5224.

Stanford, N., Djakovic, A., Shollock, B.A., McLean, M., D'Souza, N. \& Jennings, P.A. (2004) Seeding of single crystal superalloys-role of seed melt-back on casting defects. Scr. Mater. 50, 159-163.

Sun, C.-C. \& Ryum, N. (1992) Crystallographic aspect of cellular solidification. Mater. Charact. 29, 381-386.

Takatani, H., Gandin, C.A. \& Rappaz, M. (2000) EBSD characterisation and modelling of columnar dendritic grains growing in the presence of fluid flow. Acta Mater. 48, 675-688.

Trager-Cowan, C., Manson-Smith, S.K., Cowan, D.A., et al. (2001) Characterisation of nitride thin films by electron backscattered diffraction. Mater. Sci. Eng. B82, 19-21.

Ueda, M., Yasuda, H. \& Umakoshi, Y. (2004) Reverse transformation in Fe-Ni bicrystals. ISIJ Int. 44, 1924-1930.

Une, K., Nogita, K., Ishimoto, S. \& Ogata, K. (2004) Crystallography of zirconium hydrides in recrystallized zircaloy-2 fuel cladding by electron backscatter diffraction. J. Nucl. Sci. Technol (Jpn). 41, 731-740.

Une, K. \& Ishimoto, S. (2006) EBSP measurements of hydrogenated Zircaloy-2 claddings with stress-relieved and recrystallised annealing conditions. J. Nucl. Mater. 357, 147-155.

Wang, S.C., Aindow, M. \& Starink, J. (2003) Effect of self-accommodation on $\alpha / \alpha$ boundary populations in pure titanium. Acta Mater. 51, 24852503.

Watanabe, T. (1984) An approach to grain boundary design for strong and ductile polycrystals. Res. Mech. 11, 47-84.

Watanabe, T., Obara, K. \& Tsurekawa, S. (2004) In-situ observations on interphase boundary migration and grain growth during $\alpha / \gamma$ phase transformation in iron alloys. Mater. Sci. Forum 467-470, 819-824.

Watanabe, T., Obara, K., Tsurekawa, S. \& Gottstein, G. (2005) A mechanism of plane matching boundary-assisted $\alpha / \gamma$ phase transformation in Fe-Cr alloy based on in-situ observations. Z. Metallkd. 96, 1196-1203.

Wright, S.I. \& Cotton, J.D. (1995) Microtextural characterization of a beryllium weldment. Text. Microstruct. 23, 7-19.

Wright, S.I., Field, D.P. \& Nowell, M.M. (2005) Impact of local texture on recrystallization and grain growth via in-situ EBSD. Mater. Sci. Forum 495-497, 1121-1130.

Xu, X., Ward, R.M., Jacobs, M.H., Lee, P.D. \& McLean, M. (2002) Treering formation during vacuum arc remelting of Inconel 718: Part 1. Experimental investigation. Metall. Mater. Trans. 33A, 1795-1804.

Yokomizo, T., Enomoto, M., Umezawa, O., Spanos, G. \& Rosenberg, R.O. (2003) Three-dimensional distribution, morphology and nucleation site of intragranular ferrite formed in association with inclusions. Mater. Sci. Eng. A344, 261-267.

Zaafarani, N., Raabe, D., Singh, R.N., Roters, F. \& Zaefferer, S. (2006) Three-dimensional investigation of the texture and microstructure below a nanoindent in a $\mathrm{Cu}$ single crystal using 3D EBSD and crystal plasticity finite element simulations. Acta Mater. 54, 1863-1876. 
Zaefferer, S. (2000) New developments of computer-aided crystallographic analysis in transmission electron microscopy. J. Appl. Cryst. 33, 10-25.

Zaefferer, S., Ohlert, J. \& Bleck, W. (2004) A study of microstructure, transformation mechanisms and correlation between microstructure and mechanical properties of a low alloyed TRIP steel. Acta Mater. 52, 2765-2778.

Zaefferer, S., Ishikawa, S. \& Stein, F. (2008a) Distinction of different Laves phases types by EBSD in a TiCr diffusion couple: robust detection of subtle differences in EBSD patterns. Fifteenth EBSD Meeting (ed. by B. Wynne), (abstract only). Royal Microscopical Society, Oxford.

Zaefferer, S., Wright, S.I. \& Raabe, D. (2008b) Three-dimensional orientation microscopy in a focused ion beam-scanning electron microscope: a new dimension of microstructure characterization. Metall. Mater. Trans. 39A, 374-389.

Zeghadi, A., Forest, S., Gourgues, A.-F., Bouaziz, O. (2007) Ensemble averaging stress-strain fields in polycrystalline aggregates with a constrained surface microstructure-Part 2: crystal plasticity. Philos. Mag. 87, 1425-1446.

Zhang, Y., Vincent, G., Dewobroto, N., German, L., Zhao, X., Zuo, L. \& Esling, C. (2005) The effects of thermal processing in a magnetic field on grain boundary characters of ferrite in a medium carbon steel. $J$. Mater. Sci. 40, 903-908.

Zhang, Y.D., Esling, C., Gong, M.L., Vincent, G., Zhao, X. \& Guo, L. (2006) Microstructural features induced by a high magnetic feld in a hypereuutectoid steel during austenitic decomposition. Scr. Mater. 54, 1897-1900.

Zhao, J.-C. (2006) Combinatorial aproaches as effective tools in the study of phase diagrams and composition-structure-property relationships. Prog. Mater. Sci. 51, 557-631.

Zimmermann, F. \& Humbert, M. (2002) Determination of the habit plane characteristics in the $\beta-\alpha^{\prime}$ phase transformation induced by stress in Ti-5Al-2Sn-4Zr-4Mo-2Cr-1Fe. Acta Mater. 50, 17351740 . 